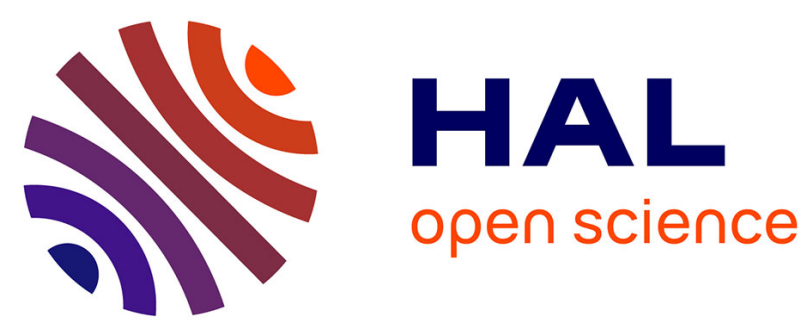

\title{
Analysis of the density effects on the source-sink dynamics in Sugar-Beet growth
}

Sébastien Lemaire, Fabienne Maupas, Paul-Henry Cournède, Jean-Michel Allirand, Bertrand Ney, P. de Reffye

\section{- To cite this version:}

Sébastien Lemaire, Fabienne Maupas, Paul-Henry Cournède, Jean-Michel Allirand, Bertrand Ney, et al. Analysis of the density effects on the source-sink dynamics in Sugar-Beet growth. Third International Symposium on Plant Growth Modeling, Simulation, Visualization and Applications (PMA09), Nov 2009, Beijing, China. 454 p. inria-00543137

\section{HAL Id: inria-00543137 \\ https://hal.inria.fr/inria-00543137}

Submitted on 5 Dec 2010

HAL is a multi-disciplinary open access archive for the deposit and dissemination of scientific research documents, whether they are published or not. The documents may come from teaching and research institutions in France or abroad, or from public or private research centers.
L'archive ouverte pluridisciplinaire HAL, est destinée au dépôt et à la diffusion de documents scientifiques de niveau recherche, publiés ou non, émanant des établissements d'enseignement et de recherche français ou étrangers, des laboratoires publics ou privés. 


\title{
Analysis of the density effects on the source-sink dynamics in Sugar-Beet growth
}

\author{
Sébastien Lemaire ${ }^{1,2,3}$, Fabienne Maupas ${ }^{1}$, Paul-Henry Cournède ${ }^{4,5}$, Jean-Michel Allirand ${ }^{6}$, \\ Bertrand Ney ${ }^{3}$, Philippe de Reffye ${ }^{2,5}$ \\ ${ }^{1}$ Institut Technique de la Betterave sucrière, 45 rue de Naples, 75008 Paris, France \\ ${ }^{2}$ CIRAD, UMR AMAP, TA-A51/PS2, Boulevard de la Lironde, 34398 Montpellier Cedex 5, Montpellier, France \\ ${ }^{3}$ AgroParisTech, UMR Environnement et Grandes Cultures, 78850, Thiverval-Grignon \\ ${ }^{4}$ Ecole Centrale Paris, Laboratory of Applied Mathematics, Grande Voie des Vignes, 92295 Châtenay Malabry, \\ France \\ ${ }^{5}$ INRIA Saclay Île-de-France, Digiplante, 91893 Orsay, France \\ ${ }^{6}$ INRA, UMR Environnement et Grandes Cultures, 78850, Thiverval-Grignon
}

Email:lemaire@itbfr.org

\begin{abstract}
- Background and Aims This paper aims at studying the capacity of an individual-based morphogenetic crop model of sugar beet growth - GreenLab - to predict the effects of population density on growth and yield.

- Methods A field experiment was carried out for three homogeneous population densities to measure detailed plant development and growth of one cultivar. A set of in situ measurements were used to observe some model inputs (organs' expansion times and life-spans) and destructive data of dry masses were collected for model calibration.

- Keys Results and Conclusions For all density conditions, the plasticity of total biomass production and allocation patterns was accurately simulated using the sets of optimized parameters. Most of them reveal stable across different spacing, and a few parameters vary with density: specific blade mass, time of phyllochron increase, petiole sink and the characteristic surface used to compute Beer's law at individual level. These results are a first step towards developing a predictive capacity regarding crop spacing.
\end{abstract}

\section{Introduction}

The most popular crop models were built from the observation that yield is closely related to the intercepted solar radiation and therefore to the leaf area index (LAI), for example SUCROS [1]. However, this key variable LAI is difficult to estimate and may need some recalibration during growth (with remote sensing techniques for example [2]) or does not take into account hard stresses (in the context of low input management, in the case of pest attacks or disease). Leaf area controls the interception of radiation, and consequently the early establishment of leaf canopy in the season improves yield. Therefore, any factor reducing the speed of leaf surface expansion directly decreases the final yield. Increase in leaf area index depends on the rate at which new leaves appear and expand, on their final sizes and how long they are retained by plants [3][4][ㄷ]. All these factors strongly depend on the environment (climate, irrigation, fertilization, agricultural practices including crop density...). In a context of sustainable agriculture and low input crop management, it is important to better understand plant physiology under stress conditions. [6] reported that if the land area that the foliage of an individual plant covers is represented by a circle, then the maximum radius is $25,5 \mathrm{~cm}$. In this condition, all the land is exploited and yield is maximized. Usually, biomass yield increases asymptotically with density, but not sugar yield, which reaches a maximum for 75.000 plants/hectare. The understanding and the extrapolation of these experimental results, in given conditions, for a given cultivar, would benefit from the insights of modeling, and more particularly of individual-based models. This paper aims at studying the capacity of an individual-based morphogenetic model of plant growth, GreenLab, to predict the effects of population density on growth and yield.

The GreenLab model can be seen as an intermediate between Process Based Models and Functional Structural Plant Models [7]. The model does not claim to be fully mechanistic with regards to physiological 
and biophysical processes and fluxes involved in plant growth but a particular care is taken to follow empirically the dynamics of the carbohydrate budget, production and allocation []. In [9], it was shown to be well-adapted to describe sugar beet development and growth. Moreover some preliminary studies used GreenLab to analyze the effects of density on maize growth [10] and tomato growth [11]. GreenLab is thus a good candidate to developing a predictive capacity with respect to population density.

The model is briefly recalled in Section 2, especially how the density effect is taken into account in the model [12]. A field experiment was carried out for three homogeneous population densities and is also described in Section 2. The results of these experiments and of model calibration are presented in Section 3. Finally, the predictive capacity of the model is discussed as well as the perspectives of this research.

\section{Materials and methods}

\subsection{GreenLab model for sugar beet growth}

The main hypothesis to compute functional growth in GreenLab is that the biomass produced by each non senescent leaf is stored in a common pool of reserves and redistributed among all organs in expansion according to their sink strengths. A sugar beet plant is composed of three types of organs: blades, petioles, and taproot. The initial seed and the green leaves are sources and petioles, blades (including the venation system) and taproot are sinks.

The time unit to compute the ecophysiological functioning (resource acquisition and allocation) is chosen to coincide with the time unit of the morphogenetic sequence based on phytomer appearance. This developmental process is driven by the phyllochron (the thermal time interval between two successive phytomers), and is called growth cycle (GC).

Therefore, the individual plant is described as a discrete dynamical system. At growth cycle $n$, the empirical equation of neat dry matter production $Q_{n}$ is derived from Monteith's equation [13] at crop level and is given by:

$$
Q_{n}=P A R_{n} \mu S^{p}\left[1-\exp \left(-k_{B} \frac{S_{n}}{S^{p}}\right)\right]
$$

where $P A R_{n}$ is the photosynthetically active radiation accumulated during growth cycle $n, \mu$ is plant Light Use Efficiency (LUE), $S_{n}$ is the leaf surface area of the plant at cycle $n, k_{B}$ is the Beer-Lambert extinction coefficient and $S^{p}$ is an empirical coefficient corresponding to a characteristic surface (related to the two-dimensional projection of space potentially occupied by the plant onto $x-y$ plane). Since this surface increases with the development of foliage, and saturates at canopy closing, we propose to model $S^{p}$ as a function of $S_{n}$ :

$$
S_{n}^{p}=S_{0}^{p}\left(1-\exp ^{\frac{S_{n}}{S_{0}^{p}}}\right)^{\alpha}
$$

where $S_{0}^{p}$ and $\alpha$ are empirical parameters estimated from experimental data.

At every growth cycle, the biomass thus produced is allocated to organs individually according to their relative demands called sink strengths. The sink strength of an organ depends on its type " $o$ " (" $b$ " for blade, " $p$ " for petiole and " $r$ " for taproot), the sink variation $P^{o}$ is given classically in GreenLab as a function of its age $j$ (in growth cycles). In sugar beet, the expansion time widely varies from one phytomer to another, and is determined for blades and petioles according to their topological rank $k: T_{b, k}$ and $T_{p, k}$. The sink variation of an organ of type $o$, of rank $k$ and chronological age $j$ is ([9]):

$$
P_{o, k}(j)=P_{o} f_{a_{o}, b_{o}}\left(\frac{T_{o}}{T_{o, k}} j\right)
$$

with

$$
f_{a_{o}, b_{o}}(j)=\frac{1}{M_{o}}\left(\frac{j+0.5}{T_{o}}\right)^{a_{o}-1}\left(1-\frac{j+0.5}{T_{o}}\right)^{b_{o}-1} \text {, }
$$$$
M_{o} \text { chosen such that: } \sup _{j} f_{a_{o}, b_{o}}(j)=1 \text { and }
$$
$T_{o}=\max _{k} T_{o, k}$.

A specific change in biomass allocation at canopy closing leads us to consider a variable petiole sink ([9]):

$$
P_{p, k}(j)=\left(p_{p}+q_{p} I_{k}\right) f_{a_{o}, b_{o}}\left(\frac{T_{o}}{T_{o, k}} j\right)
$$

where $I_{k}$ denotes the competition index at growth cycle $k$ defined by: 
$I_{k}=1-\frac{S_{k}^{p}\left(1-\exp \left(-k_{B} \frac{S_{k}}{S_{k}^{p}}\right)\right)}{k_{B} S_{k}}$

At each growth cycle $n$ of its expansion period, an organ of age $i$ receives a biomass increment $\Delta q_{o}(n, i):$

$$
\Delta q_{o}(n, i)=P_{o}(i) \frac{Q_{n}}{D_{n}}
$$

and its accumulated biomass $q_{o}(n, i)$ is thus given by the sum of all these increments since its appearance :

$$
q_{o}(n, i)=\sum_{j=0}^{i} \Delta q_{o}(n-i+j, j)
$$

If we assume a constant specific blade mass (SBM), the surface area of a given leaf is directly deduced by dividing the accumulated biomass of its blade by SBM.

The total green leaf area $S_{n}$ used in the production equation is the sum of the surface areas of all the non senescent leaves. It implies determining for all phytomers the leaf life-span, that is to say the number of growth cycles between appearance and senescence. $T_{s, k}$ will denote the life-span (in growth cycles) of the leaf borne by the phytomer of rank $k$. If the phyllochron, expansion duration $\left(T_{b, k}, T_{p, k}, T_{r}\right)$, lifespan $\left(T_{s, k}\right)$ and specific blade mass can be observed experimentally, it is not the case for the parameters: $\mu$, $S_{0}^{p}, \alpha,\left(p_{o}, a_{o}, b_{o}\right)_{o=r, p, b}, q_{p}$. They will be estimated from experimental data by model inversion, as detailed by Guo et al. [14].

\subsection{Field experiments}

Field experiments were conducted in 2008 in the Beauce plain near Pithiviers, France N48 10'12', E2 ${ }^{\circ} 15^{\prime} 7$. A single commercial cultivar, Radar was sown on April 11 with $50 \mathrm{~cm}$ between rows and two different lengths between seed-plots, $18 \mathrm{~cm}$ and $12 \mathrm{~cm}$, which corresponds to sown densities of respectively 11.1 (classical density) and 16 seeds $/ \mathrm{m}^{2}$ (high density). The most uniform sections within a large sugar beet field were selected for the trials after plant emergence. This emergence stage (corresponding top the date when $80 \%$ of the final population is reached) occurred on March 28. Two weeks after emergence, one section of classical sown density $\left(11.1 \mathrm{seeds} / \mathrm{m}^{2}\right)$ is selected and one plant out of two is removed to get a low density. Finally the final populations were measured to be 5.4, 10.9 and 16.4 plants $/ \mathrm{m}^{2}$. Irrigation and fertilization were similar for all densities.

Daily mean values of air temperature $\left({ }^{\circ} \mathrm{C}\right)$, solar radiation $\left(\mathrm{MJ} / \mathrm{m}^{2}\right)$, relative humidity $(\%)$ as well as total daily rainfall $(\mathrm{mm})$ and potential evapotranspiration or PET $(\mathrm{mm})$ were obtained from French meteorological advisory services (Météo France) $5 \mathrm{~km}$ away from the experimental site.

\subsection{Development and growth measurements}

Leaf development (appearance, expansion and senescence) was measured weekly non-destructively on the same group of 15 representative adjacent plants and for the three population densities studied. Coloured plastic rings were put around the petioles of the $1^{\text {st }}, 5^{\text {th }}$, $15^{\text {th }}, 20^{\text {th }}$, and $25^{\text {th }}$ phytomers for an easier differentiation. Blade lengths and widths as well as petiole lengths were measured on these marked phytomers.

The phyllochron is defined as the thermal time interval that separates the emergence of successive leaves. We consider that a leaf has appeared when its length reaches $10 \mathrm{~mm}$. The curve giving the product of blade length time blade width as a function of the thermal time was fitted with a logistic equation (see. Lemaire et al. [9]) to determine the expansion times, $T_{b, k}$ and $T_{p, k}$ for a phytomer $k$. A leaf was supposed senescent when its full surface is yellow. We thus determined $T_{s, k}$. The expansion time for taproot is obtained from a long period experiment (without harvesting at the usual time) conducted at ITB in 2006 and estimated to be $4527^{\circ} \mathrm{Cdays}$.

Destructive biomass measurements were carried out at seven different stages during the growth period: May $20\left(340^{\circ} \mathrm{Cdays}\right.$, since emergence with base temperature of $\left.\quad 0^{\circ} \mathrm{C}\right)$, June $11 \quad\left(703.4^{\circ}\right.$ Cdays), June 18 (804. $3^{\circ}$ Cdays), June 26 (961.8 ${ }^{\circ}$ Cdays), July 9 (1199. $4^{\circ}$ Cdays), August $12 \quad\left(1863.3^{\circ}\right.$ Cdays $)$ and September $17\left(2466.5^{\circ} \mathrm{Cdays}\right)$. For the first three dates and the last two, 15 individual plants were selected (randomly) and the dry mass of every individual organ (blades, petioles and root storage) was measured. For the all stages, we measured the fresh matter at the level of organ compartments (total mass of blades that of petioles and taproot mass) for 30 plants; a subsampling of 3 plants was used to determine the rate of dry matter if necessary. Dry matter was obtained by drying for 48 hours at $75^{\circ} \mathrm{C}$. The final stage of measurements corresponds to harvest. For this date, the 
fifteen plants selected for in-situ measures were fully described (at organ level). For all plants measured at organ level, every leaf was digitalized in order to estimate its blade surface area.

\section{Results}

\subsection{Model parameterization according to population density}

\subsubsection{Leaf appearance}

For the three densities, the number of phytomers is plotted against thermal time in Figure 1. Two distinct intervals can be observed. The phyllochron of the first phase is constant among seasons and experimental treatments (sowing dates, $\mathrm{N}$-content, plant density) as confirmed by three years of ITB experiments in various environmental conditions (data not shown).

In our experiments, the rate of leaf appearance decreases gradually with the increase of competition for light. Many hypotheses were suggested by Milford et al. in 1985 [4] to explain the curve bending: base temperature that changes when the plant gets older, photoperiodic factor and trophic competition (competition for assimilates between the developing storage root and vegetative organs). This competition may slow down the rate of leaf appearance. The density effect is quite strong on this second phase, especially regarding when it starts.

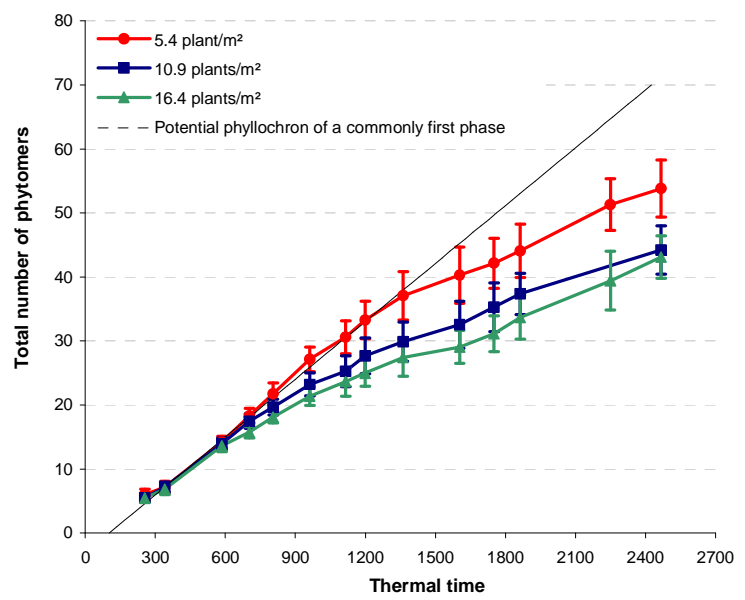

Figure 1: Number of phytomers as a function of the thermal time for the three density treatments

Therefore, for the three densities, the growth cycle is based on the common phyllochron $=30.8^{\circ} \mathrm{C}$.j (see [9] for the accurate definition of the growth cycle) and the second phase is modeled by a discrete approximation of the ratio of appearance rates between the two phases - called rhythm ratio - (see also [9] for a more accurate description). The start and ratio of these changes of appearance rates vary with density see Table 1 .

\begin{tabular}{c|lc}
$\begin{array}{l}\text { Density } \\
\text { (plants/m²) }\end{array}$ & $\begin{array}{l}\text { Rhythm } \\
\text { Ratio }\end{array}$ & $\begin{array}{l}\text { Start of } 2^{\text {nd }} \text { phase } \\
\text { on phytomer rank }\end{array}$ \\
\hline $\mathbf{5 . 4}$ & 0.57 & $18^{\text {th }}$ \\
$\mathbf{1 0 . 6}$ & 0.57 & $21^{\text {st }}$ \\
$\mathbf{1 6 . 4}$ & 0.58 & $35^{\text {th }}$
\end{tabular}

Table 1: Estimated rhythm ratio and corresponding phytomer rank to the start of change of appearance rate for the three studied densities

\subsubsection{Leaf expansions and life spans}

The important works of Milford in $1985[\underline{3}, \underline{4}, \underline{5}]$, suggested that density has no effect on leaf expansion time and life spans. Our experiments confirm his observations. The expansion kinetics of the eleventh phytomer (corresponding to the product of its blade length and width against thermal time since emergence) is shown in Figure 2. It is interesting to note that the relative growth rate of expansion is more important in low density than high density, but that blade final sizes are reached at the same time. Such observation is done for all the phytomers.

In Figure 3 are shown the observed leaf life spans of all phytomers for the three densities. The variations between treatments can be neglected.

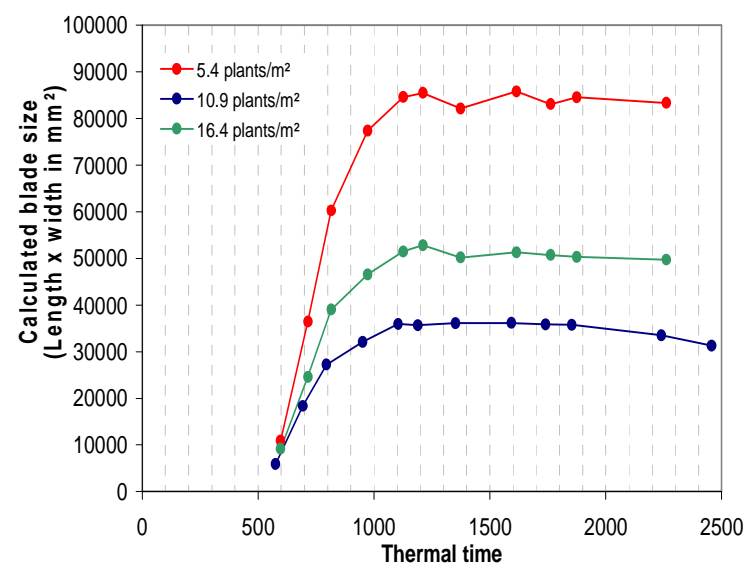

Figure 2: Expansion kinetics of the blade of the 11th phytomer for the 3 studied densities 


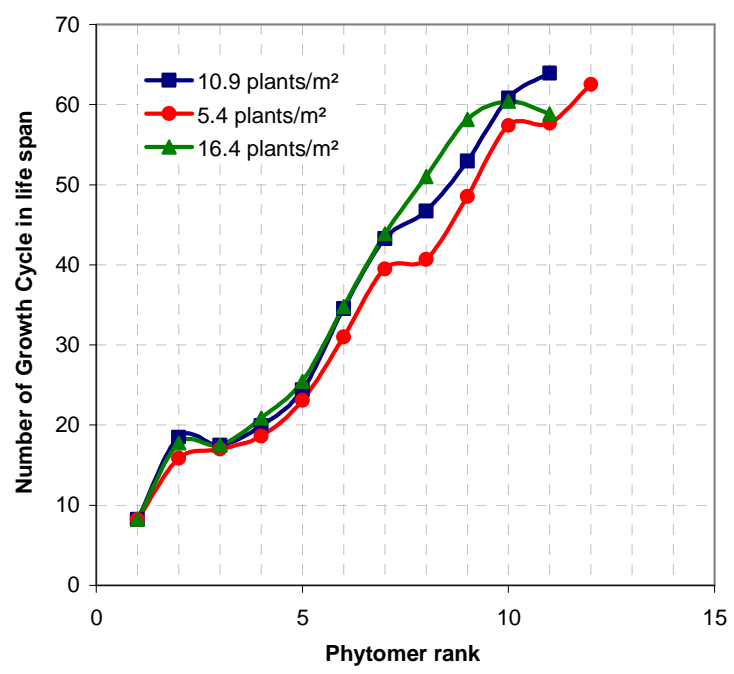

Figure 3: Leaf life spans (in growth cycles) according to phytomer rank for the 3 studied densities

\subsubsection{Specific Blade Mass}

The specific blade mass is defined as the ratio of blade dry mass to blade surface area. Figure 4, plots one variable against the other for all measured data (different plants at different ages, one color for each density treatment). We observe a linear relationship between the two variables for the three densities, even though the dispersion increases for bigger leaves. Furthermore SBM decreases with population density.

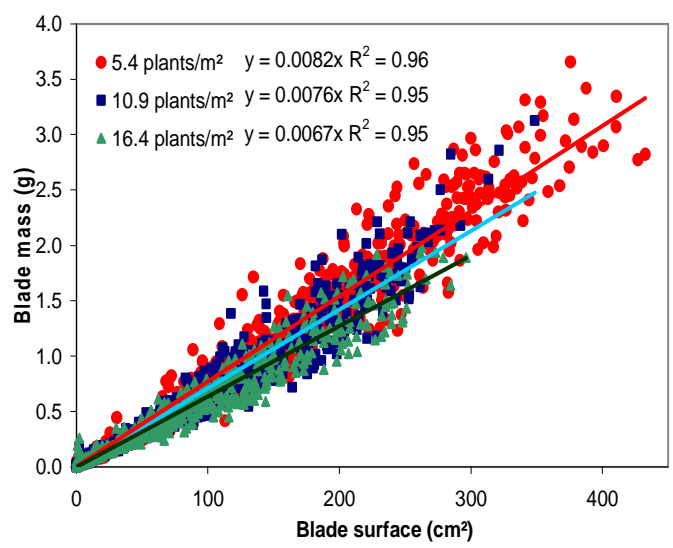

Figure 4: Blade Masses against Surface Area for all the measured leaves and for the three studied densities

\begin{tabular}{c|ccc}
\hline Densité & $\mathbf{5 . 4}$ pl.ha $^{-1}$ & $\mathbf{1 0 . 9}$ pl.ha $^{-1}$ & $\mathbf{1 6 . 4}$ pl.ha $^{-1}$ \\
& & & \\
\hline SBM $\left(\mathbf{g} / \mathbf{c m}^{2}\right)$ & 0.0082 & 0.0076 & 0.0067 \\
\hline
\end{tabular}

Table 2: Estimated SBM for the three studied densities

\subsubsection{Beer-Lambert Extinction Coefficient}

The Beer-Lambert Extinction coefficient $k_{B}$ depends on the geometric and spectral properties of the canopy. For Sugar Beet, Andrieu et al. [15] found a relationship linking this coefficient to density, with small variations around 0.7 , and deduced that it only has a small incidence on final production. Hodáñová [16] reported its value to 0.69 in 1969. Therefore, we choose to fix $k_{B}=0.7$ for all densities.

\subsection{Estimation of Hidden Parameters from Experimental Data}

In order to fully parameterize the model, we also need to determine the hidden parameters (summarized in Table 3).

\begin{tabular}{lc} 
Parameter & Description \\
\hline$\mu(g / M J)$ & Radiation use efficiency \\
$S_{0}^{p}, \alpha$ & $\begin{array}{c}\text { Empirical coefficient corresponding to } \\
\text { asymptotical value of a characteristic surface } \\
p_{b}\end{array}$ \\
$p_{p}$ & dynamical function: $S_{n}^{p}$ \\
$q_{p}$ & Plade sink strength \\
$a_{b}, b_{b}$ & Petiole sink strength \\
$a_{p}, b_{p}$ & Parameter for blade sink variation function \\
$a_{r}, b_{r}$ & Parameter for root sink variation function
\end{tabular}

Table 3: Summary of model hidden parameters to estimate 
The data on which we calibrate the model correspond to average data on all the individual plants measured at the seven stages: average profile of organ masses when available, and average organ compartments. The calibration is done with Digiplant software [17] by model inversion. However, since no specific identification tool dedicated to the study of density exists, the identification process is not fully automatic: the calibration is first done for each density independently, and then we see what parameters are not significantly different for all treatments and can be fixed to a common value. Once this set of common parameters is fixed, we run the calibration process again for each treatment. This can be done iteratively, until fixing the maximum number of parameters while keeping a comparable quality of adjustment to the data.

The parameters thus obtained for the three studied treatments are given in Table 4, and the fitting results are given in Figure 5 for the compartment masses (at 7 stages), and in Figure 6 for the blade organ masses (at every phytomer rank, and at 5 stages).

\begin{tabular}{cccccc}
\hline Parameter & Type* & $\begin{array}{c}\mathbf{5 . 4} \\
\mathbf{p l} / \mathrm{m}^{2}\end{array}$ & $\begin{array}{c}\mathbf{1 0 . 9} \\
\mathbf{p l} / \mathrm{m}^{2}\end{array}$ & $\begin{array}{c}\mathbf{1 6 . 4} \\
\mathbf{p l} / \mathrm{m}^{2}\end{array}$ & Unit \\
\hline$\mu$ & $\mathrm{E}$ & & 26.042 & & $\mathrm{~g} / \mathrm{MJ}$ \\
$S_{0}^{p}$ & $\mathrm{E}$ & 0.024 & 0.012 & 0.007 & $\mathrm{~m}^{2}$ \\
$\alpha$ & $\mathrm{F}$ & & 0.3 & & - \\
$p_{r}$ & $\mathrm{~F}$ & & 400 & & - \\
$p_{b}$ & $\mathrm{~F}$ & 1 (reference value) & - \\
$p_{p}$ & $\mathrm{E} \& \mathrm{~F}$ & 0.5 & 0.5 & 0.5 & - \\
$q_{p}$ & $\mathrm{E}$ & 0.165 & 0.293 & 0.627 & - \\
$a_{r}$ & $\mathrm{E} \& \mathrm{~F}$ & & 4.5 & & - \\
$b_{r}$ & $\mathrm{E} \& \mathrm{~F}$ & & 3.5 & & - \\
$a_{b}$ & $\mathrm{E} \& \mathrm{~F}$ & & 3 & & - \\
$b_{b}$ & $\mathrm{E} \& \mathrm{~F}$ & & 2 & & - \\
$a_{p}$ & $\mathrm{E} \& \mathrm{~F}$ & & 3 & & - \\
$b_{p}$ & $\mathrm{E} \& \mathrm{~F}$ & & 4 & & - \\
\hline
\end{tabular}

*Estimated (E) Measured (M) or Fixed (F)

Table 4: Estimated parameters for all density treatments
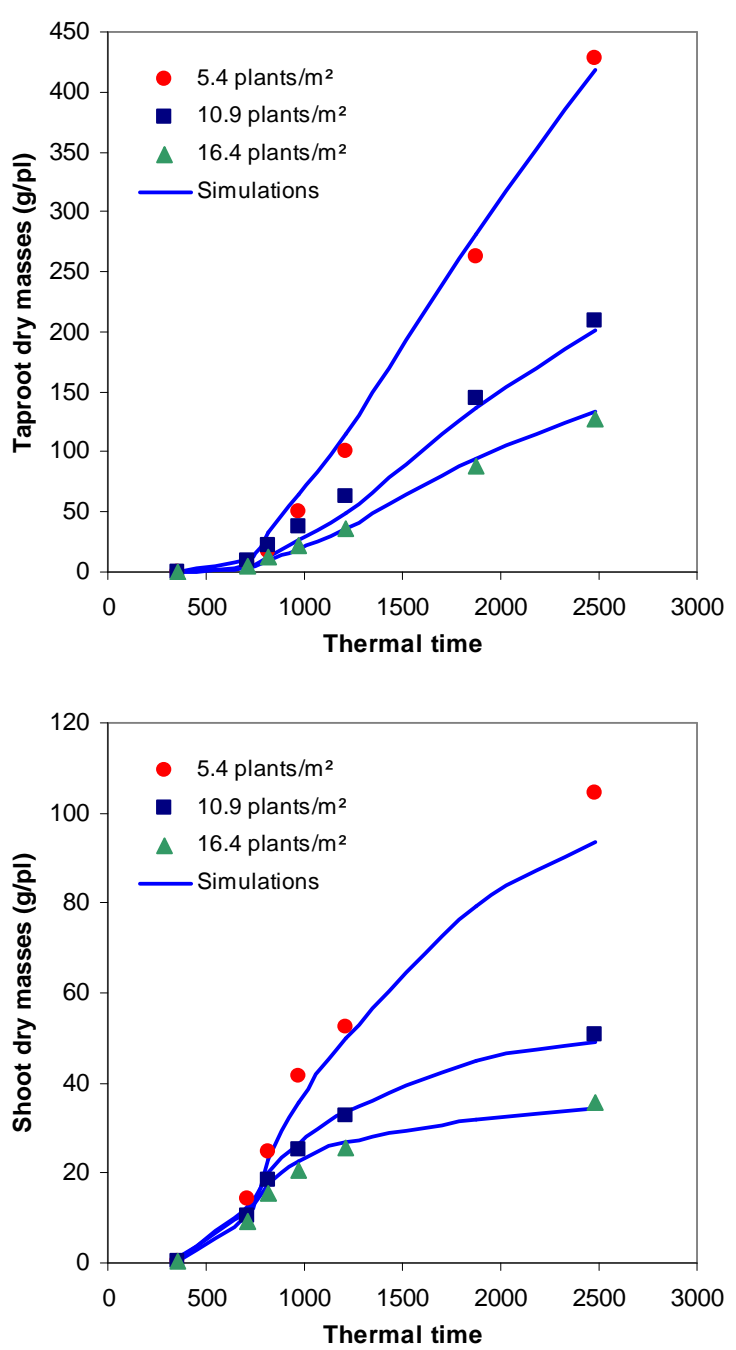

Figure 5: Average plants at compartment level: experimental data (dots) and simulated data (lines) for three density treatment. (a) Taproot compartment dry mass and (b) Shoot (i.e. blades and petioles dry mass) as function of thermal time since emergence

The interesting point when considering the final results of parameter estimation is the strong stability of parameters across density treatment. Only three of the estimated parameters vary.

The first one is the Radiation Use Efficiency. However, we recall that the Radiation Use Efficiency thus estimated is at plant level, with a PAR given in $\mathrm{MJ} / \mathrm{m}^{2}$. To get the Radiation Use Efficiency per $\mathrm{m}^{2}$, for the closed canopy, we need to multiply $\mu$ by $S_{0}^{p}$ and by the density, which finally gives very similar radiation use efficiencies of $3.29,3.18$ and $3.16 \mathrm{~g} / \mathrm{MJ}$ for respective densities of $5.4,10.9$ and 16.4 plantes $/ \mathrm{m}^{2}$. 
The second parameter that varies is $S_{0}^{p}$ which is the saturation limit of $S_{n}^{p}$. Theoretically, we expected that $S_{0}^{p}$ would be the inverse of the density, since it should correspond to the space potentially available for the plant. It is not the case, but the ratio of $S_{0}^{p}$ to the inverse of the density seems to be (relatively) constant. Finally, the coefficient of petiole sink strength correction also varies, and increases drastically with the density. Such result is in keeping with was observed in maize [10], and tomato [11]: in order to overcome competition for light, a plant will tend to invest more in its petioles, to intercept more light.

\section{Conclusion}

This study is a first step to develop a predictive model that would allow the inference of source-sink dynamics of Sugar Beet growth at any density. Of course, there is a strong need for validation among seasons and in different environmental conditions. However, we can exhibit the base of what could be such model. It would consist in determining stable relationships linking SBM, the decrease of the rate of leaf appearance, petiole sink strength correction and $S_{0}^{p}$ to the density. The GreenLab model could thus be applied straightforwardly with density as an input. It thus opens perspectives for applications, to optimize density, especially in the context of low input crop management, since a low density crop should also require less water, nitrogen, pesticides ...

However, the results obtained seem to show some hints of improvements, in terms of parameter stability and predictive capacity. Regarding the decrease of phytomer appearance rate, it does not seems directly related to density but more to some competition index, since the differences of the rate appearance (during the second phase of development) were also observed in other experiments to study Nitrogen stresses: plants enduring Nitrogen stresses had smaller foliage and more phytomers than plants without stresses.

Likewise, the coefficient of petiole sink strength correction was introduced in Lemaire et al. [9] to take into account the variation of petiole sink strength after canopy closing, by introducing this dependence to a competition index. We would have expected that this competition index, which includes density effect, would be sufficient to fully take into account the density effect. Estimation results show that it is not the case.
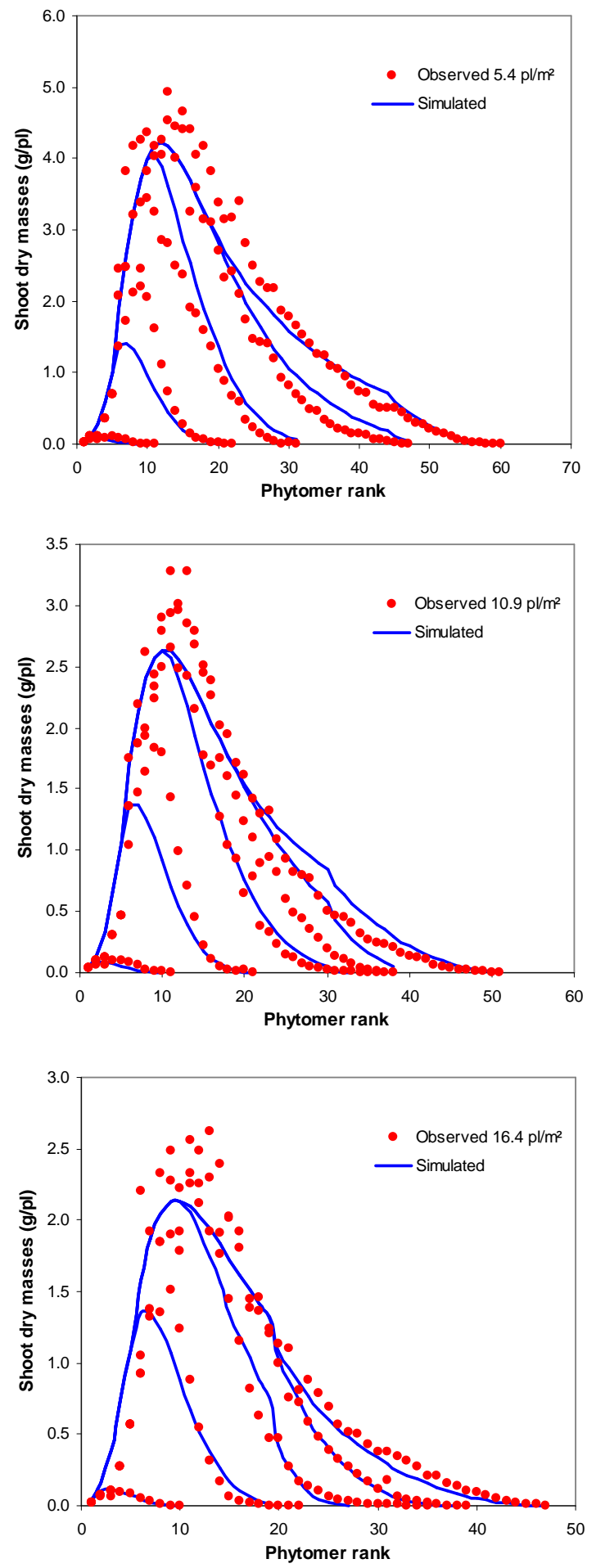

Figure 6: Average plants of shoot dry masses organ level according to phytomer rank: experimental data (dots) and simulated data (lines) for three density treatments (a) 5.4 plants. $\mathrm{m}^{-2}$ (b) 10.9 plants. $\mathrm{m}^{-2}$ and (a) 16.4 plants. $\mathrm{m}^{-2}$ 
Finally, as underlined above, we expected to find a better agreement between $S_{0}^{p}$ and the inverse of density. Even though the ratio between the two variables seems constant for different densities, the results may indicate that we are missing an element in the individual-to-population extrapolation.

To conclude, we would like to insist on the strong stability of GreenLab model parameters in the different density conditions, few of them are sufficient to take into account the effects of competition for light. Parameter stability is a key issue in plant growth modeling and its link to plant genetics [18], since each genotype should be represented by a set of response parameters that are valid under a wide range of conditions [19].

\section{References}

[1] C.J.T. Spitters, H. van Keulen, and D.W.G. van Kraalingen, "Simulation and Systems Management in Crop Protection. A simple and universal crop growth simulator: SUCROS87”, R. Rabbinge et al. (eds.), Wageningen, 1989

[2] M. Launay, and M. Guerif, "Assimilating remote sensing data into a crop model to improve predictive performance for spatial applications", Agriculture, Ecosystems and Environment, 2005, v.111 pp 321-339

[3] J.F.G. Milford, T.O. Pocock, and J. Riley, "An analysis of leaf growth in sugar-beet. I. Leaf appearance and expansion in relation to temperature under controlled conditions", Annals of Applied Biology, 1985, v. 106 pp. $163-172$

[4] J.F.G. Milford, T.O. Pocock, and J. Riley, "An analysis of leaf growth in sugar-beet. II. Leaf appearance in field crops", Annals of Applied Biology, 1985, v. 106 pp. 173-185 [5] J.F.G. Milford, T.O. Pocock, J. Riley, and A.B. Messem, "An analysis of leaf growth in sugar-beet. III. Leaf expansion in field crops", Annals of Applied Biology, 1985, v. 106 pp. $187-203$

[6] K.W. Jaggard, and A. Qi, "Sugar Beet: Chapter 7 Agronomy", A.P. Draycott (ed.), Blackwell Publishing, Oxford, 2006

[7] P. de Reffye, E. Heuvelink, D. Barthelemy, and P.-H. Cournède, "Encyclopedia of Ecology vol.4: Plant Growth Models", S.E. Jorgensen and B. Bath (eds.), Oxford, 2008

[8] H.P. Yan, M.Z. Kang, P. de Reffye, and M. Dingkuhn, "A dynamic, architectural plant model simulating resourcedependent growth", Annals of Botany, 2004, v. 93 pp. 591602

[9] S. Lemaire, F. Maupas, P.-H. Cournède, and P. de Reffye, "A morphogenetic crop model for sugar-beet (Beta vulgaris L.)" Proceeding of the International Symposium on Crop Modelling and Decision Support ISCMDS', Nanjing, 2008

[10] Y.T. Ma, M.P. Wen, Y.Guo, B.G. Li, P.-H. Cournède, and P. de Reffye, "Parameter optimization and field validation of the functional-structural model GREENLAB for maize at different population densities", Annals of Botany, 2008, v. 101 pp. $1185-1194$

[11] Q.X. Dong, G. Louarn, Y.M. Wang, J.F. Barczi, and P. de Reffye, "Does the Structure-Function model GREENLAB Deal with Crop Phenotypic Plasticity Induced by Plant Spacing? A case Study on Tomato", Annals of Botany, 2008, v. 101 pp. $1195-1206$

[12] P.-H. Cournède, A. Mathieu, F. Houllier, D. Barthelemy, and P. de Reffye, "Computing competition for light in the Greenlab model of plant growth: a contribution to the study of the effects of density on resource acquisition and architectural development", Annals of Botany, 2008, v. 101 pp. 1207-1219

[13] J.L. Monteith, "Climate and the efficiency of crop production in Britain", Proc. of the Royal Society of London, 1977

[14] Y. Guo, Y.T. Ma, Z.G. Zhan, B.G. Li, M. Dingkuhn, D. Luquet, and P. de Reffye, "Parameter optimization and field validation for the functional-structural model GREENLAB for maize", Annals of Botany, 2006, v. 97 pp. 217-230

[15] B. Andrieu, J.M. Allirand, and K.W. Jaggard, "Ground cover and leaf area index of maize and sugar beet crops", Agronomie, Agronomie, 1997, v.17 pp. 315-321.

[16] D. Hodáñová, "Structure and development of sugar beet canopy. I. Leaf angle relations.", Photosynthetica, v.6 pp. 401-409

[17] P.-H. Cournède, M.-Z. Kang, A. Mathieu, J.F. Barczi, H.P. Yan, B.G. Hu, and P. de Reffye, «Structural factorization of plants to compute their functional and architectural growth", Simulation, 2006, v. 82 pp. 427-438

[18] V. Letort, P. Mahe, P.-H. Cournède, P. de Reffye, and B. Courtois. "Quantitative genetics and functional structural plant growth models: simulation of quantitative trait loci detection for model parameters and application to potential yield optimization." Annals of Botany, 2008, v.101 pp 12431254

[19] F. Tardieu, "Virtual plants: modelling as a tool for the genomics of tolerance to water deficit", Trends Plant Science, 2003, v.8 pp. 9-14 